\title{
[1EV/SSIÓN
}

\section{El tejido adiposo: algo más que un reservorio de energía}

\author{
Por Alfonso Valenzuela $B^{1,2^{*}}$ y Julio Sanhueza $C^{1}$ \\ ${ }^{1}$ Centro de Lípidos, INTA, Universidad de Chile, Casilla 138-11, Santiago, Chile. \\ ${ }^{2}$ Facultad de Medicina, Universidad de los Andes, Santiago, Chile. \\ ( ${ }^{\star}$ Autor para la correspondencia: avalenzu @ inta.cl)
}

\section{RESUMEN}

\author{
El tejido adiposo: algo más que un reservorio de \\ energía
}

El tejido adiposo es un reservorio de grasa y también un órgano que contribuye a la estética y a la salud de las personas, tarea que cumple funcionando como un tejido endocrino. El tejido adiposo blanco, formado por células adiposas uniloculares puede regular la homeostasis orgánica entre el gasto y el consumo de energía. Produce una serie de adipokinas que regulan el consumo de alimentos, la utilización de glucosa y de lípidos por parte del organismo. El tejido adiposo pardo o marrón, estructurado por células multiloculares, contiene numerosas gotas de grasa de pequeño tamaño, las que pueden ser hidrolizadas con mayor facilidad. El tejido participa en la termogénesis adaptativa o facultativa debido a la proteína desacoplante-1 (UCP-1) que inhibe la síntesis de ATP produciendo calor. Con la edad, este tejido se reduce y por ello actualmente se considera que una forma de combatir la obesidad es lograr que el tejido adiposo blanco adquiera característica de pardo. Este trabajo revisa las principales características estructurales y funcionales del tejido adiposo blanco y pardo, con énfasis en sus funciones reguladoras y endocrinas.

PALABRAS CLAVE: Adipokinas - Regulación de temperatura - Tejido adiposo blanco - Tejido adiposo pardo.

\section{SUMMARY}

The adipose tissue: something more than a reservoir of energy

Adipose tissue is a reservoir of energy and also an organ that contributes to the aesthetics and health of human body working as an endocrine tissue. White adipose tissue, which is formed by unilocular adipose cells, can modify organic homeostasis by controlling energy expenditure and consumption and by producing adipokines that regulate food consumption, and carbohydrate and lipid metabolic utilization. Brown adipose tissue is structured by multilocular cells containing many small fat drops that can be easily hydrolyzed. This tissue is involved in adaptative or facultative thermogenesis because it contains the uncoupling- 1 protein (UCP-1) which by inhibiting ATP synthesis releases heat. The size of brow adipose tissue is reduced with aging and the most recent future strategies to fight obesity may be by transforming white cells into brown adipose tissue. The present work reviews the main structural and functional characteristics of white and brown adipose tissue with emphasis in its endocrine and regulatory function.
KEY-WORDS: Adipokines - Brown adipose tissue Temperature regulation - White adipose tissue.

\section{INTRODUCCIÓN}

Es común para muchos de nosotros el que a lo largo de nuestra existencia vaya modificándose el peso corporal, particularmente con la acumulación de tejido adiposo donde antes no lo teníamos, con lo cual se modifica, a veces lamentándolo mucho, nuestra imagen física. Sin embargo, sin menospreciar el efecto poco estético de la acumulación de grasa, esta se torna más grave cuando cobra importancia clínica-patológica impactando muy negativamente nuestra salud. La relación entre el sobrepeso-obesidad y el desarrollo de las enfermedades crónicas no transmisibles es una realidad con gran evidencia científica. Sin embargo, es común asociar al tejido adiposo solo como un reservorio energético. La evidencia actual nos indica que las células que constituyen este tejido, los adipocitos y otras que las acompañan, tienen una gran variedad de funciones, todas ellas muy relacionadas con la regulación de la homeostasis corporal. En esta revisión abordaremos las funciones del tejido adiposo, desde un punto de vista más allá que el ser solo un reservorio de energía.

\section{EL TEJIDO ADIPOSO, SU ESTRUCTURA BÁSICA}

Fisiológicamente el tejido adiposo es considerado como un órgano difuso de gran actividad metabólica. Aproximadamente entre el 15 al $25 \%$ del peso corporal de una persona adulta (hombres $15 \%-20 \%$, > 25\% se considera obesidad; mujeres $20 \%-25 \%$, > 33\% se considera obesidad) está representado por el tejido adiposo siendo este, como lo sabemos, una importante reserva energética (Cinti, 2005). Histológicamente el tejido adiposo, visto como un órgano, no está formado solamente por los adipocitos, ya que estos constituyen aproximadamente el $60 \%-70 \%$ de su estructura. El tamaño de los adipocitos puede variar considerablemen- 
te desde 20 a 200 micrómetros de diámetro, lo que significa que pueden en ciertas circunstancias aumentar hasta 1000 veces su volumen. El resto del tejido está constituido por células sanguíneas, células endoteliales, macrófagos, pericitos y precursores de los adipocitos en distintos grados de diferenciación, ya sean fibroblastos como precursores primarios y preadipocitos que son células intersticiales vacías de lípidos y prontas a transformarse en adipocitos (Poissonnet et al., 1984; Hausman, 1987). La proliferación y activación de macrófagos en el tejido adiposo se ha relacionado con los estados inflamatorios que se asocian con la obesidad como patología. Aunque el origen embrionario de las células grasas no es del todo conocido, las investigaciones realizadas sugieren que la línea adipocitaria deriva de un precursor embrionario multipotencial de estructura fusiforme que posee la capacidad para diferenciarse en distintas células especializadas (adipocitos, condrocitos, osteoblastos y miocitos) las que finalmente forman parte de la estructura de diferentes tejidos (Geloen et al., 1989). Los procesos celulares que llevan a la conversión de las células multipotentes en adipoblastos y posteriormente en preadipocitos y adipocitos, son todavía poco conocidos, aunque en la actualidad se reconocen mecanismos que permiten aproximarnos con mayor certeza sobre lo que ocurre en la formación del tejido adiposo. Las principales funciones del tejido adiposo son: reserva energética, amortiguación-protección ósea y aislamiento térmico, aunque como veremos, también ahora se acepta que posee funciones endocrinas y paracrinas (Gregoire, 1998; Vázquez-Vela et al., 2008).

La importancia del tejido adiposo dentro de las especies presenta una gran variabilidad. En los invertebrados el tejido adiposo representa un órgano nutricionalmente importante, particularmente en los insectos, y su importancia disminuye en los arácnidos, crustáceos y moluscos. En los vertebrados el desarrollo del tejido adiposo es un signo evolutivo en los organismos homeotermos. También su proporción en el peso corporal varía notoriamente entre las especies (cerca del $40 \%$ del peso corporal de los cetáceos lo constituye el tejido adiposo), las reservas grasas de las aves migratorias y las reservas de los mamíferos también presentan gran diferencia, pero constituyen un ejemplo de la importancia en la actividad metabólica de este tejido. El desarrollo del tejido adiposo, en especial del tejido adiposo blanco presenta gran diferencia entre las especies. Este no puede ser detectado microscópicamente durante la etapa embrionaria ni en el nacimiento de la mayoría de los roedores, mientras que sí está presente desde el nacimiento en los conejos, cerdos, conejillos de indias y en los humanos. El 14\% del peso corporal del recién nacido humano esta constituido por el tejido adiposo, el cual comienza su formación a partir de la semana 14 de gestación. El aumento postnatal es más marcado en los primeros 3 meses de vida, probablemente ligado a la pobre capacidad de termorregulación corporal a esa edad. Curiosamente, dentro de los mamíferos el humano es el que nace con mayor cantidad de tejido adiposo (Hager, 1977). La figura 1 muestra comparativamente el contenido de tejido adiposo de diferentes especies.

Histológicamente, el tejido adiposo blanco esta altamente vascularizado (aunque menos que el tejido adiposo pardo), a tal punto que muchos adipocitos se encuentran en contacto directo con uno o más capilares. Estos permiten la entrada y salida activa de metabolitos, péptidos y factores no peptídicos fundamentales en la regulación de la diferenciación y el crecimiento celular. Las células endoteliales del tejido adiposo, como los fibroblastos y otras células de origen mesenquimal, incluyendo los preadipocitos y los adipocitos maduros, secretan un factor de crecimiento similar a la insulina (IGF-1), siendo al parecer una de las principales moléculas reguladoras involucradas en la hiperplasia del tejido adiposo durante la embriogénesis y en la infancia (Salans et al., 1973; Hager, 1977; Cinti, 2006).

Se ha logrado identificar dos etapas de crecimiento acelerado del tejido adiposo blanco, una después del nacimiento, ya mencionada, y otra que se produce durante el predesarrollo puberal, entre los 9 y 13 años de edad. La tasa de proliferación del tejido adiposo decrece en la adolescencia y se presenta un equilibrio relativo hasta la adultez (Salans et al., 1973). Normalmente la expansión del tejido adiposo se debe principalmente a hipertrofia de las células ya presentes (aumento del tamaño celular), sin un aumento en el número de células (hiperplasia). Sin embargo, una vez que se desencadenan los mecanismos que conducen a la obesidad, se produce un aumento no solo del tamaño de las células adiposas, también un aumento del número de células, las que pueden hasta quintuplicar el número original determinado en la postadolescencia. La disminución del tamaño de las células es más fácil que la disminución del número de adipocitos. Por esta razón en muchos casos los regímenes dietéticos tendientes a disminuir la obesidad en los adultos fracasan, porque solo se logra disminuir el tamaño de los adipocitos y no la cantidad de estos,

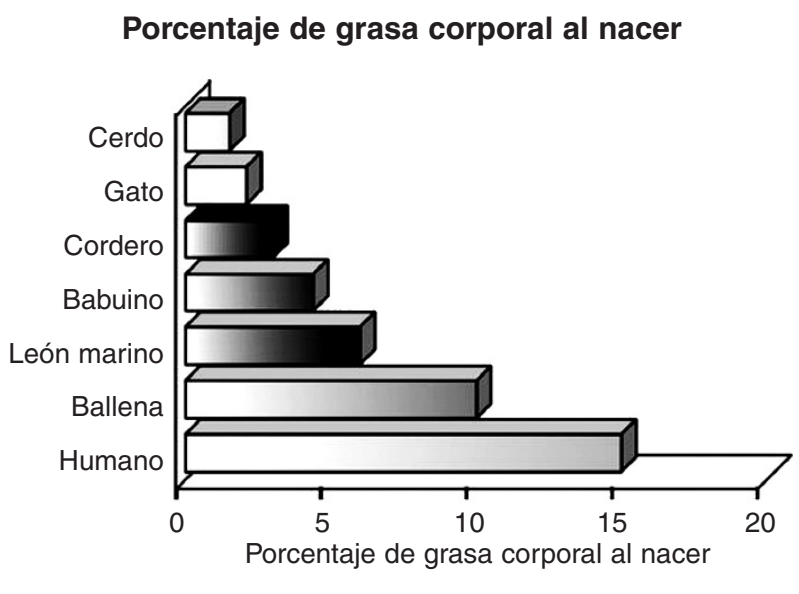

Figura 1

Porcentaje de grasa corporal de diferentes especies animales al nacer. 
con lo cual estas células tienden a recuperar su tamaño original en poco tiempo (Hirsh \& Batchelor, 1976).

Generalmente el tejido adiposo se deposita en áreas con abundante tejido conectivo laxo, como por ejemplo las capas subcutáneas entre el músculo y la dermis. Sin embargo, también se localiza en forma típica, alrededor de las vísceras, riñones, corazón y otros órganos internos. Muchos estudios avalan el hecho de que el tejido adiposo no es un órgano homogéneo. Mas aún, se plantea que la ubicación topográfica del tejido adiposo hace que tenga perfiles metabólicos distintos dependiendo de la ubicación anatómica, lo cual lo hace susceptible de participar en el desarrollo de ciertas patologías. Por ejemplo, la localización intra abdominalvisceral tiene más efectos patológicos que la localización subcutánea (Garaulet et al., 2006). La figura 2 ejemplifica las diferencias entre la grasa subcutánea y visceral.

\section{TIPOS DE TEJIDO ADIPOSO}

Aún persiste una de las más antiguas clasificaciones del tejido adiposo y que tiene como base la coloración que este adquiere ante tinciones fundamentales utilizadas en anatomía patológica. Es así como se le clasifica en tejido adiposo blanco y tejido adiposo pardo o marrón.

\subsection{Tejido adiposo blanco}

Estructuralmente es unilocular (de estructura intracelular uniforme) y no es exactamente de color blanco en los primates, más bien de color amarillo variando a diferentes tonalidades las que dependen principalmente de la dieta del individuo, mientras mayor es el contenido de carotenoides dietarios, mas intenso es el color amarillo del tejido. Estructuralmente cada adipocito contiene una gota central grande de triacilglicéridos (estructura unilo-

\section{Diferencias entre la grasa subcutánea y visceral}

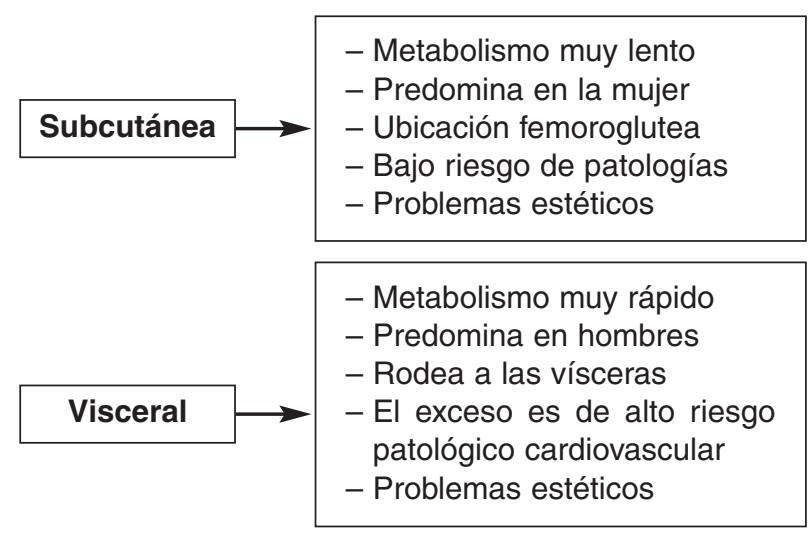

Figura 2

Diferencias anatómicas y metabólicas entre la grasa subcutánea y la grasa visceral. cular) y el citoplasma queda reducido a un fino reborde de la célula. El núcleo, de estructura oval, desplazado hacia la zona periférica, contiene cromatina de grano fino y no presenta un nucléolo visible. El adipocito del tejido adiposo blanco posee pocas mitocondrias, un retículo endoplasmático rugoso y liso de baja densidad membranosa y un complejo de Golgi de pequeño tamaño. La gota de lípido está limitada por pequeños filamentos proteicos denominados perilipinas (Subramanian et al., 2004). Como ya se mencionó, el tejido adiposo blanco es muy vascularizado, cada célula está en contacto con al menos un capilar. Este tejido está subdividido en pequeños lobulillos por tabiques de tejido conectivo no muy definidos. Esta segmentación es más visible en las zonas donde la función de este tejido es la amortiguación, por ejemplo, la zona glútea, encontrándose tabiques de tejido conectivo grueso que dividen la zona en diferentes capas (Cinti, 2006; Garaulet et al., 2006).

En el ayuno, las células adiposas blancas liberan gradualmente los lípidos almacenados y la vacuola central disminuye de tamaño. El tejido adiposo blanco se encuentra distribuido como grasa subcutánea (tejido adiposo subcutáneo) y como panículo adiposo en el mesenterio y en la zona retroperitoneal (tejido adiposo visceral). En los niños, una capa de grasa uniforme cubre todo el cuerpo, mientras que en los adultos el tejido se acumula en algunas zonas específicas, siendo ésta distribución distinta por género: en la mujer suele acumularse en la región mamaria, cadera, región glútea y muslos, mientras que en el hombre suele acumularse en la nuca, región lumbo-sacra y región glútea. En ciertas zonas corporales, no se produce liberación de lípidos durante el ayuno, como es el caso del tejido graso correspondiente a la zona periorbicular de los ojos, rodillas, palmas de las manos, plantas de los pies. En los últimos dos casos el tejido adiposo cumple una función básicamente de tipo mecánico como elemento de sostén y amortiguación (Mauriege et al., 1999; Kuk \& Ross, 2009).

\section{Tejido adiposo subcutáneo}

Es cuantitativamente el más importante constituyendo alrededor de un $80 \%$ del total de la grasa corporal. Su metabolismo es más bien lento en comparación con el tejido adiposo visceral. Esto es, los procesos de lipogénesis y lipogenólisis, discutidos más adelante, son de poca relevancia. El tejido adiposo subcutáneo de la región abdominal tiene un comportamiento mixto en términos metabólicos ya que puede ser tan activo como el visceral. Su función más destacada es la de aislante térmico y de amortiguación mecánica. También se ha propuesto que ejercería un efecto de "amortiguación metabólica" ya que podría de alguna manera amortiguar el impacto de los excesos calóricos en el tejido adiposo visceral, aunque este aspecto no está aún del todo claro (Sethi \& Vidal-Puig, 2007; Bakker et al., 2004). 


\section{Tejido adiposo visceral}

También es conocido como tejido adiposo intraperitoneal. Se le subdivide en omental y mesentérico y se ubica en las regiones profundas de la cavidad abdominal rodeando las vísceras. Constituye el $5 \%-10 \%$ del tejido adiposo total en mujeres y hombres, respectivamente, siendo similar este porcentaje en individuos de peso normal y obesos (Sethi \& Vidal-Puig, 2007). Las mujeres, en la edad adulta y postmenopausia tienden a aumentarlo más que los hombres (Kuk \& Ross, 2009). Metabólicamente es más activo que el tejido adiposo subcutáneo en relación a los procesos de lipogénesis y de lipólisis, lo cual está determinado por una abundancia de receptores adrenérgicos lipolíticos y antilipolíticos (ver más adelante). Posee, además, receptores para glucocorticoides, con lo cual las situaciones de estrés crónico tienen gran impacto sobre los depósitos de grasa en este tejido, pudiéndose producir estímulo de su acumulación, o por el contrario, de su movilización (aumento o baja de peso en condiciones de estrés físico y/o emocional). Desde el punto de vista vascular, está sujeto a drenaje portal, con lo cual los ácidos grasos que se liberan por lipólisis llegan directamente al hígado, constituyendo así un aporte directo de energía para el metabolismo general. Sin embargo, un exceso de drenaje de ácidos grasos desde el tejido adiposo visceral al hígado, también facilita el desarrollo de insulinorresistencia hepática, hiperinsulinemia, dislipidemia e hiperglicemia. Su asociación con una mayor prevalencia de patologías como la diabetes 2 , hipertensión, dislipidemia y cardiovasculares, ya es evidente (Bakker et al., 2004). Jean Vague definió en 1947 la clásica distribución entre grasa abdominal o androide (obesidad tipo manzana) y grasa femoroglútea o ginoide (obesidad tipo pera), relacionando a la primera con un mayor riesgo de patologías asociadas a lo que hoy identificamos como el síndrome metabólico (Vague, 1947). La figura 3 muestra las diferencias en la expresión fenotípica de ambos tipos de obesidad.

\subsection{Tejido adiposo pardo}

Topográficamente el tejido adiposo pardo se encuentra principalmente alrededor del cuello y los grandes vasos sanguíneos del tórax en los neonatos para luego ser subsecuentemente reemplazado en los adultos por el tejido adiposo blanco, aunque en los adultos se conserva tejido adiposo pardo, en pequeños cúmulos, dentro del tejido adiposo blanco (Poissonnet et al., 1984). El tejido adiposo pardo permite realizar lo que se conoce como termogénesis adaptativa o facultativa, esto es la capacidad que tiene el organismo para responder al frío.

A diferencia del tejido adiposo blanco, el tejido adiposo pardo es multilocular, esto es formado por múltiples gotitas citoplasmáticas de diferente tamaño conteniendo triacilglicéridos. Sus células son más pequeñas que las del tejido adiposo blanco, pero contienen una cantidad considerablemente

\section{Expresión fenotípica del exceso de grasa corporal} (obesidad)

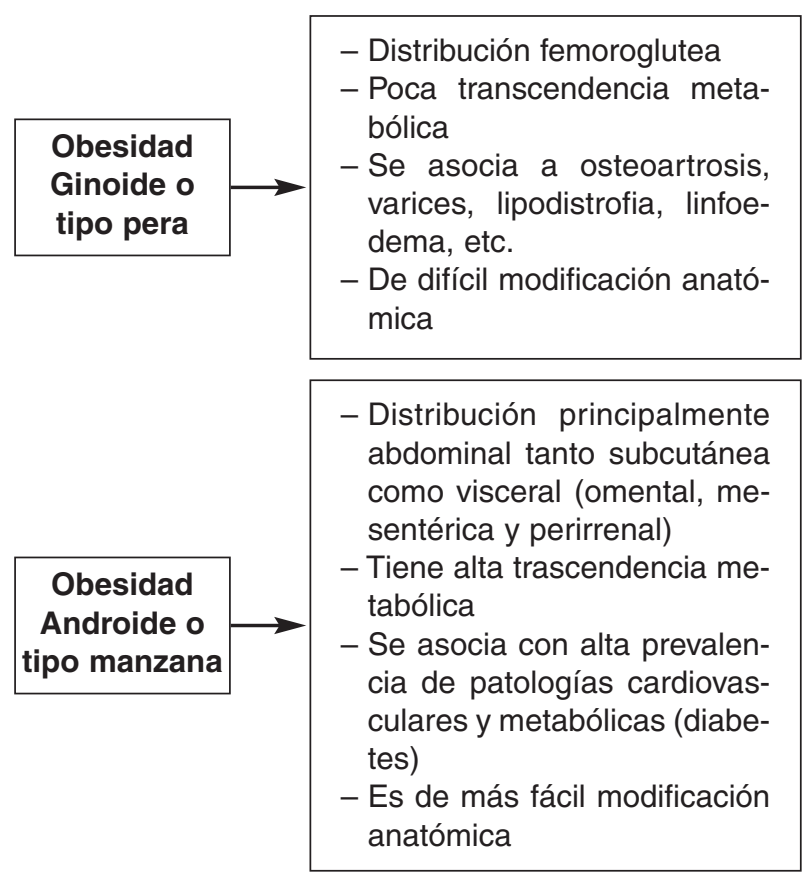

Figura 3

Diferente expresión fenotípica del exceso de grasa corporal de tipo ginoide y androide.

mayor de mitocondrias. Su color varía desde el dorado al marrón rojizo y sus células tienen forma poligonal, exhibiendo un citoplasma más abundante y granuloso. El núcleo es redondeado, está ubicado un poco excéntrico y contiene gránulos de cromatina bastante gruesos y con un nucléolo visible. En el citoplasma se observan numerosas mitocondrias grandes y redondas que presentan crestas muy juntas. Los demás organelos se encuentran poco desarrollados. El tejido adiposo pardo aparece a la microscopía característicamente lobulado y puede parecer una glándula en cuanto a su aspecto macroscópico. Presenta muchos más capilares que el tejido adiposo blanco, y posee numerosas fibras nerviosas entre sus células. El color marrón está dado por los citocromos que forman parte de la cadena respiratoria de las numerosas mitocondrias que posee (Cannon \& Nedergaard, 2004).

El tejido adiposo pardo se encuentra muy desarrollado en los neonatos, constituyendo entre el 2 al $5 \%$ del peso corporal y se encuentra entre las escápulas, en las axilas, en la región de la nuca y rodeando a lo largo los vasos sanguíneos grandes. El tejido adiposo pardo se va modificando con la edad transformándose en tejido adiposo blanco. La principal función del tejido adiposo pardo es mantener la temperatura corporal en el neonato (Asakura, 2004). Los animales superiores deben mantener su temperatura corporal dentro de un margen muy estrecho. En el desarrollo embrionario y fetal, el nuevo ser se encuentra aislado de la temperatura ambiental por lo cual no posee termorregulación. En el momento del nacimiento, el recién nacido debe hacer 
uso de una termogénesis obligatoria del metabolismo celular, y de una disipación calórica superficial, para lo cual se cuenta con el tejido adiposo pardo, el cual funciona como fuente generadora de calor después del parto. Tras el nacimiento, la hipotermia neonatal produce un estímulo del sistema nervioso que inerva el tejido adiposo pardo a través de la activación de receptores sensibles a la temperatura situados en el hipotálamo y en la médula espinal. Este tejido es estimulado por la noradrenalina secretada por el sistema nervioso autónomo, produciéndose la hidrólisis aumentada de triacilglicéridos de los adipocitos por activación de la lipasa hormona sensible (LHS), y luego la oxidación de ácidos grasos por beta oxidación mitocondrial que va acompañada de gran consumo de oxígeno, produciéndose calor durante este proceso, el cual mantiene caliente al neonato. Una proteína identificada como termogenina actúa como un factor desacoplante entre la respiración mitocondrial y la fosforilación oxidativa, de modo que se forma menos ATP y se disipa mayor cantidad de calor (Bhakoo, 1974; Price, 1994; Stephenson, et al., 2001). La termogenina pertenece a un grupo de proteínas desacoplantes colectivamente conocidas como UCP (UnCoupling Protein), las que juegan una función muy importante en el control de la termogénesis, especialmente en los animales que hibernan. Las UCP son 5 , la UCP-1 se encuentra solo en el tejido adiposo pardo, la UCP-2 se distribuye en varios tejidos (músculo, riñón, vísceras), la UCP-3 solo se encuentra en el músculo esquelético, y las UCP-4 y UCP-5 se ubican en el cerebro. Se ha observado en recién nacidos con retraso de crecimiento intrauterino y/o con menor edad gestacional, la presencia de hipoglicemia, hipoxia y trastornos en la producción de calor, lo cual ocasiona inestabilidad térmica (Bianco \& Silva, 1987; Symonds et al., 1992; Hesselink, 2003). Esto se debe a que el neonato no presenta un adecuado desarrollo del tejido adiposo pardo, por lo cual los depósitos de energía en la forma de triacilglicéridos no son suficientes. El tejido adiposo pardo posee tres tipos de receptores adrenérgicos:
Receptores tipo beta: Su activación estimula a la enzima adenilato-ciclasa, lo cual aumenta las concentraciones intracelulares de AMPc, produciendo la activación de una proteina kinasa que a su vez por fosforilación activa a la LHS, iniciando así la liberación de ácidos grasos los que no abandonan los adipocitos pardos, siendo beta oxidados por sus abundantes mitocondrias. La máxima expresión de estos receptotes se produce en el momento del nacimiento y permanecen activos durante toda la lactancia (Cannon \& Nedergaard, 2004).

Receptores tipo alfa 1: Son independientes de la activación de la enzima adenilato-ciclasa. La activación de las proteínas kinasas, que a su vez activan a la LHS, se produce a través del aumento del calcio intracelular producido por la activación de estos receptores. De esta forma, su acción es complementaria a la activación de los receptores beta adrenérgicos (Cannon \& Nedergaard, 2004).

Receptores tipo alfa 2: Su activación inhibe a la enzima adenilato-ciclasa, con lo cual disminuye la concentración de $\mathrm{AMPc}$, por lo tanto son antitermogénicos. Estos receptores disminuyen a medida que se acerca la hora del nacimiento, favoreciendo así la función termogénica del tejido adiposo pardo en el recién nacido, derivada de la activación de los receptores beta y alfa 1 (Cannon \& Nedergaard, 2004). La figura 4 esquematiza la respuesta del tejido adiposo pardo a distintos estímulos hormonales.

El tejido adiposo pardo tiene gran cantidad de mitocondrias con crestas largas y apiladas (lugar donde ocurre la fosforilación oxidativa), por lo tanto está capacitado para una oxidación activa donde la energía liberada no está ligada a la fosforilación oxidativa sino que es empleada en la producción de calor (Argyropoulos \& Harper, 2002). El tejido adiposo pardo aumenta el número de mitocondrias durante los últimos días del desarrollo fetal y después del nacimiento estos organelos aumentan considerablemente su volumen. Durante la lactancia continua esta actividad, la que comienza a decaer a las pocas semanas después del nacimiento. Se ha de-

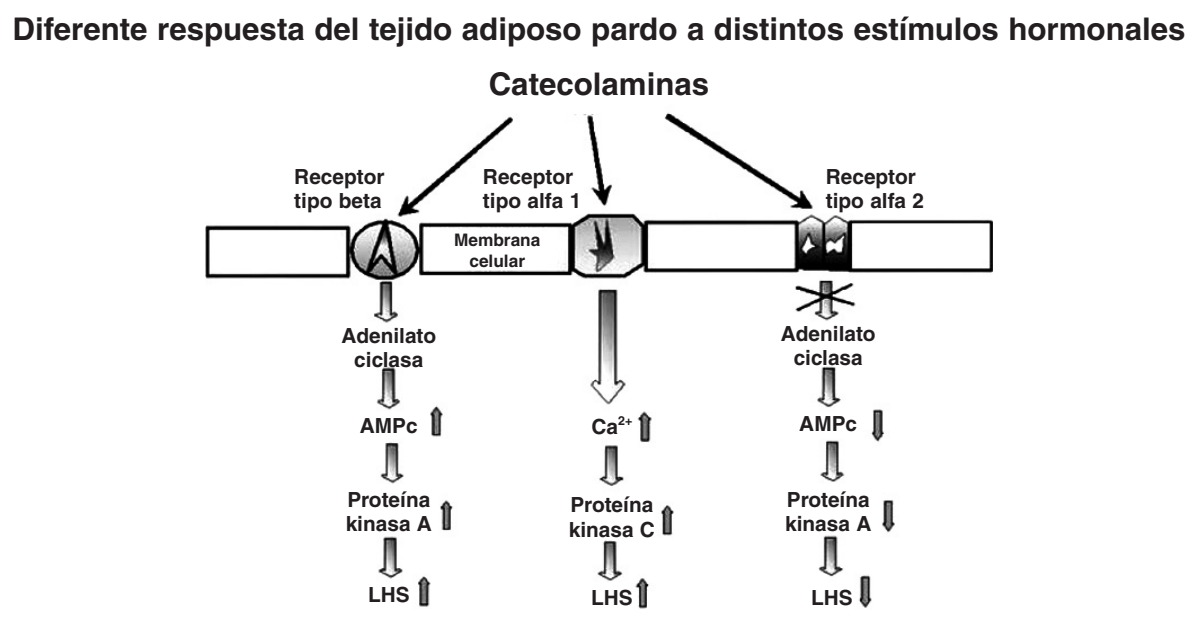

Figura 4

Respuesta metabólica del tejido adiposo pardo al estímulo producido por catecolaminas en receptores de tipo beta, alfa 1 y alfa 2 . 
mostrado que recién nacidos expuestos a una temperatura de 25 grados Celsius aumentan la captación de oxígeno, aumentando la temperatura en la piel y en zonas específicas donde se acumula el tejido adiposo pardo (Asakura, 2004). Se ha evaluado el efecto de la exposición al frío en el tejido adiposo pardo y en la termogénesis en neonatos ovinos, valorando diferentes parámetros como: consumo de oxígeno y la producción de $\mathrm{CO}_{2}$, demostrándose el efecto del frío sobre el tejido adiposo pardo, donde se observa que en los primeros días postnatales se produce el mayor incremento del consumo de oxígeno (de hasta un 40\%) y de la temperatura rectal, lo cual denota una actividad termogénica acelerada. De esta forma, se ha concluido que, el incremento en la actividad termogénica del tejido adiposo pardo, en recién nacidos ovinos, está relacionado directamente con la exposición al frío en los primeros días de vida. En roedores se ha evidenciado que los principales factores reguladores de la actividad termogénica del tejido adiposo pardo son la adrenalina, la insulina y la producción de triyodotironina (Bianco \& Silva, 1987; Symonds et al., 1992).

Aparentemente, después de todo el desarrollo energético del tejido adiposo pardo, éste evoluciona hacia un estado energético de reposo, que supone la acumulación de lípidos en forma de una gran vacuola, dándole un aspecto unilocular a la célula, característico de las células adiposas blancas, aunque no hay certeza que se trate de una transformación total. Este tejido permanece en reposo de por vida, desde el punto de vista termogénico. Se ha propuesto que la reconversión de este tejido nuevamente en células pardas, o la transformación de células adiposas blancas en pardas, podrían constituir un interesante abordaje para el tratamiento de la obesidad mórbida. Sin embargo, aún falta mucho por conocer sobre la regulación y la biología molecular de estas células (Cannon \& Nedergaard, 2004). La figura 5 ejemplifica las diferencias morfológicas entre el tejido adiposo blanco y el tejido adiposo pardo.

\section{HISTOGÉNESIS Y FISIOLOGÍA DEL TEJIDO ADIPOSO}

\subsection{El desarrollo del tejido adiposo}

El desarrollo y la expansión del tejido adiposo in vivo está regido por una serie de acciones coordinadas de numerosos factores, que en conjunto forman una red integrada y finamente regulada, diseñada primariamente para el mantenimiento del equilibrio energético en el organismo. Factores de tipo genético, epigenéticos, ambientales y farmacológicos, estarían involucrados en esta red. Actualmente, una de las principales líneas de investigación en enfermedades metabólicas es el estudio y la diferenciación de las diferentes redes y señales que facilitan las comunicaciones entre los distintos órganos internos (Gregoire, 2001; Valet et al., 2002; Sethi \& VidalPuig, 2007). En tal sentido, se han logrado importantes avances en la comprensión de las bases moleculares del desarrollo del tejido adiposo a través de las técnicas de clonación y de caracterización de numerosos genes involucrados en la diferenciación y metabolismo del adipocito. La transgénesis, rama de la biología molecular encargada del estudio de funciones y mecanismos de acción mediante la manipulación genética, ha mostrado gran utilidad en la identificación de las funciones fisiológicas de los genes que regulan la adipogénesis (Rosen \& MacDougald, 2006; Sethi \& Vidal-Puig, 2007).

La propia naturaleza difusa del proceso de adipogénesis in vivo dificulta el estudio del reclutamiento y diferenciación de los adipocitos. Se han diseñado una serie de estratégicas que han logrado crear líneas celulares primarias inducibles capaces de diferenciarse en adipocitos in vitro, lo cual ha permitido un mejor conocimiento acerca de los mecanismos que regulan su diferenciación celular a adipocito. En general, el mecanismo mejor identificado es la secuencia de eventos transcripcionales en cascada que controla la adipogénesis (Farmer, 2006).

Los procesos implicados en la diferenciación de los precursores adipocitarios hasta adipocitos ma-

Diferencias morfológicas entre los tipos de tejido adiposo

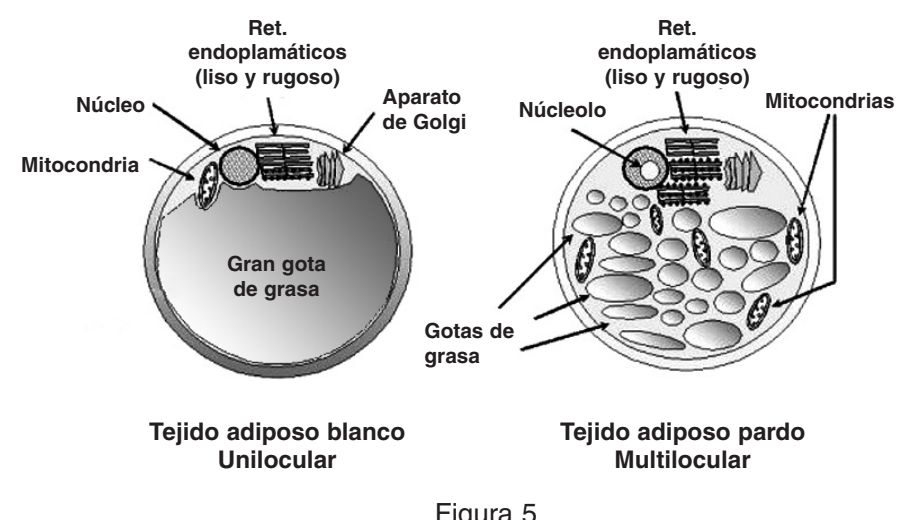

Diferencias morfológicas entre el tejido adiposo blanco (unilocular) y el tejido adiposo pardo (multilocular). 
duros han sido ampliamente estudiados utilizando modelos celulares in vitro. Estos han permitido la caracterización de los eventos moleculares y celulares que tienen lugar durante la transición de preadipocitos indiferenciados, tipo fibroblastos, hasta células grasas redondeadas maduras (Djian et al., 1985; Gregoire et al., 1998; Entingh et al., 2003). Las líneas celulares utilizadas se pueden dividir en 3 categorías: Células embrionarios totipotentes capaces de generar todas las líneas celulares; Células multipotentes que pueden dar lugar a miocitos, adipocitos y condrocito; Células ya comprometidas hacia la línea adiposa, que son las denominadas líneas celulares de preadipocitos.

Se ha logrado también el cultivo de preadipocitos primarios, así como la inducción de su transformación en adipocitos maduros, en diversas especies animales, incluido el hombre. Estas células presentan, además, la ventaja que pueden ser obtenidas desde varias especies animales en diferentes etapas del desarrollo postnatal y de diferentes depósitos grasos. Esto último es muy importante ya que se han observado importantes diferencias moleculares y bioquímicas entre los distintos depósitos grasos (Gregoire et al., 1998).

Durante la fase de crecimiento, tanto las líneas celulares de preadipocitos como los preadipocitos primarios, son morfológicamente similares a los fibroblastos (Green \&. Kehinde, 1975). Una vez que las células han alcanzado la confluencia, el tratamiento con los inductores adecuados de la diferenciación conduce a un cambio drástico en la forma de las células. Los preadipocitos se convierten en células de forma esférica que comienzan a acumular lípidos y que van adquiriendo progresivamente las características morfológicas y bioquímicas propias de los adipocitos maduros. El tratamiento capaz de inducir la diferenciación varía en los distintos modelos celulares descritos. Aunque los preadipocitos de diferentes fuentes son similares en múltiples aspectos, su respuesta a los agentes inductores de la diferenciación varía considerablemente. Estas diferencias pueden venir determinadas por el diferente estadio de maduración en el que se obtuvieron los preadipocitos. En la mayor parte de los casos se requiere la presencia de insulina (Entingh et al., 2003). En algunos casos, la diferenciación se ve acelerada tras el tratamiento durante 48 horas con dexametasona, un corticoide, o con isobutilmetilxantina (IBMX), un estimulante de la formación de AMPc, y con altas concentraciones de insulina en presencia de suero bovino fetal. Tras ese período de inducción de la diferenciación, no se requiere la presencia de estos inductores de diferenciación para el mantenimiento del fenotipo del adipocito maduro (Mandrup \& Lane, 1997).

\subsection{La diferenciación del adipocito}

La diferenciación de los adipocitos es un proceso complejo en el que los preadipocitos deben interrumpir su crecimiento y salir del ciclo celular como paso previo a su conversión terminal en adipocitos maduros. Este proceso de diferenciación supone cambios cronológicos en la expresión de numerosos genes. Así, se van expresando aquellos genes característicos de los adipocitos, al mismo tiempo que se van reprimiendo genes que son inhibitorios para la adipogénesis o que son innecesarios para la función del adipocito maduro. Todos estos cambios en la expresión y función de estos genes conducen a la adquisición del fenotipo característico del adipocito (Richon et al., 1997; Shao \& Lazar, 1997).

Aunque los fenómenos moleculares implicados en la diferenciación de los adipocitos no son totalmente conocidos, se ha sugerido un modelo que incluye varias etapas:

Inhibición del crecimiento. Una vez alcanzada la confluencia, los preadipocitos sufren inhibición por contacto y cesan su crecimiento y comienzan a exhibir algunos de los marcadores tempranos de la diferenciación.

Expansión clonal: El tratamiento de estas células en las que ha cesado el crecimiento y que ya se encuentran en etapas de diferenciación, las induce a reentrar en el ciclo celular, produciéndose varios ciclos de replicación del DNA y de duplicación celular. Esta expansión mitótica clonal de células comprometidas es esencial para completar la diferenciación terminal para transformarse en adipocitos maduros.

Cambios tempranos en la expresión de genes. La expresión de la enzima lipoproteína lipasa (LPL) ha sido considerada a menudo como un signo temprano de la diferenciación adipocitaria. La expresión de la LPL ocurre, sin embargo, de manera espontánea al alcanzar la confluencia y es independiente de los inductores de la diferenciación. Esta circunstancia sugiere que la LPL puede reflejar la etapa de cese del crecimiento más que ser un marcador temprano del proceso de diferenciación. Hasta ahora se han descrito 2 familias de factores de transcripción, las C/EBPs (CCAAT/Enhancer Binding Proteins) y el PPAR $($ Peroxisome Proliferator Activated Receptor $\gamma$ ), que han sido identificados como reguladores de la transcripción de genes adipogénicos. Las tiazolidinedionas, fármacos con acción antidiabética y que actúan como ligandos directos de PPAR $\gamma$, son además potentes y efectivos estimulantes de la adipogénesis. Estos fármacos aumentan la sensibilidad a la insulina promoviendo la diferenciación de adipocitos subcutáneos, permitiendo así la redistribución de grasa visceral, más patogénica, hacia grasa periférica de menor riesgo. Esta puede ser la razón por la que el tratamiento de la diabetes con este tipo de fármacos produce aumento del peso de los pacientes, conocido clínicamente como la "paradoja de las tiazolidinedionas". Los factores de transcripción C/EBP $\beta$ y C/EBP $\delta$ parecen jugar también un importante papel en la inducción del PPARy (LekstromHimes \& Xanthopoulos, 1998; Kowenz-Leutz \& Leutz, 1999; Rosen et al., 2000; Hausman \& Hausman, 2006). 


\section{Eventos tardíos y diferenciación terminal}

Durante la fase final de la diferenciación, los adipocitos en cultivo incrementan marcadamente la lipogénesis de novo observándose, por lo tanto, un incremento en la expresión y la actividad de las enzimas implicadas en esta ruta, tales como la enzima sintetasa de ácidos grasos, la enzima málica y la enzima glicerol-3-fosfato deshidrogenasa. Durante esta etapa, también aumenta considerablemente la sensibilidad a la insulina, debido a un gran aumento del número de receptores de insulina y de transportadores de glucosa dependientes de insulina (Glut4). La diferenciación de los adipocitos conlleva a un incremento total en el número de receptores adrenérgicos. Además, se produce un aumento de la síntesis de aP2, una proteína fijadora de ácidos grasos específica de los adipocitos, y de la perilipina, la proteína asociada en forma periférica a las gotas de lípidos. En esta etapa los adipocitos comienzan a secretar algunas sustancias endocrinas y paracrinas tales como la leptina, la adipsina, y la angiotensina (Spiegelman et al., 1983; Morrison \& Farmer, 2000; Tchkonia et al., 2002). Existe una gran variedad de factores que regulan la diferenciación de los adipocitos, tanto de carácter proadipogénico como antiadipogénico. La figura 6 muestra algunos de estos factores.

Factores reguladores de la diferenciación de los adipocitos

\begin{tabular}{ll}
\hline \multicolumn{1}{c}{ Proadipogénica } & Antiadipogénica \\
\hline Insulina & Ácido retinoico \\
Isobutil metilxantina (IBMX) & Esteres de forbol \\
Ácidos grasos poliinsaturados & Resistina \\
Tiazolidinedionas & Prostaglandina $\mathrm{F}_{2} \alpha$ \\
Prostaciclina $\mathrm{PGI}_{2}$ & Arseniato de sodio \\
Angiotensina & Interferon gamma \\
Glucocorticoides & Inhibidores mitóticos \\
Hormona de crecimiento & Factor de crecimiento \\
& epidérmico \\
\hline
\end{tabular}

Figura 6

Efecto de diferentes hormonas y de sustancias químicas en la diferenciación de los adipositos.

\section{EL TEJIDO ADIPOSO COMO ÓRGANO DE ALMACENAMIENTO}

Una de las funciones tradicionalmente bien estudiadas del tejido adiposo es su función como almacenador y liberador de energía, lo que ocurre a través de dos procesos, la lipogénesis y la lipogenólisis.

\subsection{Lipogénesis}

El tejido adiposo blanco es el mayor reservorio energético del organismo. La principal fuente de triacilglicéridos para alimentar a este tejido proviene de los quilomicrones y de las VLDL circulantes.
Los triacilglicéridos que contienen estas lipoproteínas son hidrolizados hasta ácidos grasos libres y monoacilglicerol por la LPL que se encuentra adherida a los capilares que irrigan el tejido adiposo. Los ácidos grasos son captados por los adipocitos a través de procesos de transporte activo mediados por proteínas transportadoras específicas de ácidos grasos. Una vez en el interior de la célula, los ácidos grasos son reesterificados a triacilglicéridos y depositados en el interior de la gran gota de grasa incluida en los adipocitos. El término lipogénesis de novo significa específicamente la formación de ácidos grasos a partir de algún precursor derivado del adipocito, por ejemplo, la glucosa. En los humanos, el almacenamiento de los ácidos grasos en el tejido adiposo depende prácticamente de la liberación de los mismos desde las lipoproteínas por la acción de la LPL. Sin embargo, se ha observado que pacientes con deficiencia de LPL son capaces de acumular triacilglicéridos en el tejido adiposo, lo que hace pensar en la existencia de otros mecanismos para la acumulación de triacilglicéridos, como lo sería la lipogénesis de novo (Brun et al., 1989; Ranganathan et al., 2006).

\subsection{Lipólisis}

Durante la lipólisis, los triacilglicéridos almacenados en el tejido adiposo son hidrolizados hasta ácidos grasos y glicerol. El paso limitante de este proceso está controlado por la LHS. Esta enzima cataliza la hidrólisis de los tracilglicéridos a monoacilglicéridos, los que son finalmente degradados por la enzima monoacilglicerol lipasa. La LHS está sujeta a una fina regulación y se activa por fosforilación realizada por una kinasa activada por AMPc. La lipólisis es estimulada por todos los agentes que estimulen a la enzima adenilato-ciclasa y aumenten la formación de AMPc, como ocurre con las catecolaminas que activan los receptores beta adrenérgicos. Por el contrario, la lipólisis es inhibida por aquellas hormonas que inhiban la formación de AMPc. Esto ocurre con catecolaminas que actúan a través de los receptotes alfa 2 adrenérgicos. Las catecolaminas tienen, por lo tanto, un efecto dual sobre la lipólisis y por ello su efecto lipolítico neto depende del balance entre la activación de receptores beta y alfa 2 adrenérgicos. Otras hormonas inhibitorias de la lipólisis, como es el caso de la insulina, actúan a través de receptores que están asociados a la formación de fosfatidilinositol $\left(\mathrm{IP}_{3}\right)$, otro importante segundo mensajero que regula diferentes funciones celulares (Halliwell et al., 1996; Mauriège et al., 1999).

No se sabe si la localización del tejido adiposo próxima a órganos vitales, como el corazón, ejerce solo funciones de soporte mecánico o cumple un rol metabólico como fuente local de energía. No es sorprendente que el tejido adiposo esté diseñado para responder a cambios nutricionales específicos. De hecho, los adipocitos están preparados para responder tanto a cambios hormonales como nerviosos (Gillum, 1987). 


\section{EL TEJIDO ADIPOSO COMO ÓRGANO SECRETOR-ENDOCRINO}

El descubrimiento de una serie de sustancias con efectos fisiológicos producidas por los adipocitos, permitió el descubrimiento que el tejido adiposo se comporta como un órgano endocrino, ejerciendo variadas acciones reguladoras, siendo capaz de coordinar y administrar cambios en el balance energético y en el estado nutricional general. Los estudios de microscopía electrónica han permitido identificar otros tipos de células en el tejido adiposo, las que al parecer juegan roles importantes en la regulación de la función de este tejido y su interacción con otros tejidos. Se han encontrado pericitos, células endoteliales, monocitos, macrófagos y células pluripotenciales (incluyendo preadipocitos) como parte del tejido adiposo y que estarían involucradas en la producción de varios factores endocrinos y paracrinos. Los factores secretados por el tejido adiposo, pueden tener efectos en muchos sistemas biológicos, incluyendo la homeostasis energética (metabolismo de lípidos, carbohidratos, control del apetito, termogénesis), sistema inmunológico, función reproductiva, hemostasia y angiogénesis (Ronti et al., 2006; Sethi \& Vidal-Puig, 2007).

El tejido adiposo también responde a las sobrecargas nutricionales excesivas alterando la producción de adipokinas. Se entiende por adipokina a toda proteína secretada por el tejido adiposo cuya producción está alterada en estados de obesidad y que puede afectar las complicaciones metabólicas asociadas a esta condición patológica. Se ha visto que las adipokinas participan en la regulación de la homeostasis de la glucosa en todo el cuerpo (Trayhurn, 2005). El tejido adiposo sintetiza una variada gama de adipokinas entre las que se cuentan: leptina, adiponectina, factor de necrosis tumoral alfa (TNF- $\alpha$ ), interleukina 6 (IL-6), resistina, proteína 4 que une ácido retinoico (RBP-4), visfatina, omentina. Más aún, recientemente se han descubierto otras moléculas como: serpina, lipocalina-2, PAI 1, apelina, chemerina, glicoproteína $\mathrm{Zn}-\alpha 2$, etc. Todas estas adipokinas en conjunto se encargan de integrar tanto la respuesta alimentaria como el gasto energético del organismo. La figura 7 muestra las principales adipokinas secretadas por el tejido adiposo y sus efectos metabólicos (Vázquez-Vela et al., 2008).

Una función menos conocida de estas sustancias es su potencial para mediar eventos paracrinos-autocrinos en la regulación del desarrollo, expansión y plasticidad del tejido adiposo. Es más, muchas de las mismas adipokinas implicadas en el desarrollo de la insulino resistencia inducida por la obesidad, pueden alterar el metabolismo lipídico y contribuir a alterar la distribución del tejido adiposo corporal. Además de las funciones endocrinas en cuanto al control de la ingesta de alimentos y/o del gasto energético, las adipokinas pueden actuar localmente ejerciendo efectos autocrinos o paracrinos que pueden alterar las funciones del tejido adiposo y su capacidad de expansión (Miner, 2004; Sethi \& Vidal-Puig, 2007).

\section{PAPEL DEL TEJIDO ADIPOSO EN LA SOBREALIMENTACIÓN Y DISREGULACIÓN METABÓLICA}

La presencia de un aumento sustancial de la masa grasa no explica por si sola los cambios metabólicos ni la resistencia insulínica asociada a la obesidad. Esto ha sido demostrado en modelos experimentales con roedores donde se ha podido generar resistencia periférica a la insulina, aún en ausencia de tejido adiposo (Kim et al., 2000; Tschöp \& Heiman, 2001). De hecho, la pérdida de los depósitos grasos exacerba la resistencia insulínica a través de la lipotoxicidad inducida por la hiperlipemia, lo cual explicaría en parte el porqué se encuentran desórdenes lipodistróficos en personas delgadas. Estas evidencias subrayan la importancia que el tejido adiposo tenga una serie de mecanismos de control, los que se ejercen aún en personas con cargas nutricionales normales.

Es de conocimiento general que la obesidad se explique por un aumento de la ingesta alimenticia, asociada a una disminución de la actividad física en términos termodinámicos. Sin embargo, se ha observado que la capacidad de expansión y de almacenamiento del tejido adiposo está prefijada o limitada. Antes se pensaba que el tejido adiposo se

Principales Adipokinas producidas por el tejido adiposo

\begin{tabular}{|c|c|c|}
\hline Adipokina & $\begin{array}{c}\text { Efecto en } \\
\text { ingesta de alimentos }\end{array}$ & Efecto titular \\
\hline Leptina & Anorexígena & Aumenta sensibilidad a insulina en músculo \\
\hline Adiponectina & $\begin{array}{l}\text { Disminuye o aumenta } \\
\text { según lugar de acción }\end{array}$ & Aumenta sensibilidad a insulina en músculo \\
\hline Resistina & Anorexígena & Reduce capatación de glucosa hepática \\
\hline Interleukina-6 & Anorexígena & Reduce sensibilidad a insulina en músculo \\
\hline Omentina & Sin efecto & Aumenta sensibilidad a insulina en músculo \\
\hline $\begin{array}{l}\text { Factor de necrosis } \\
\text { tumoral alta }(\mathrm{TNF}-\alpha)\end{array}$ & Anorexígeno & Reduce capatación de glucosa hepática \\
\hline
\end{tabular}

Figura 7

Efectos metabólicos de las principales adipokinas secretadas por el tejido adiposo. 
podía expandir pasivamente y acomodar cualquier exceso de nutrientes. Actualmente se sabe que el proceso de expansión del tejido adiposo, entendido como hipertrofia e hiperplasia, es un proceso complejo que requiere energía. Desde la aparición de la obesidad como epidemia, el tejido adiposo nunca ha estado sometido a tanta presión para acomodar los grandes volúmenes de tejido graso producto del aumento de ingesta alimenticia (Trayhurn, 2005; Vázquez-Vela et al., 2008).

Adicionalmente a la función del tejido adiposo como depósito de energía, se ha visto que este tejido cumple un papel importante en la regulación de la homeostasis de la glucosa. Esto se puso en evidencia en ratones en los que se bloqueó los transportadores GLUT4 de los adipocitos, provocando resistencia periférica a la insulina e intolerancia a la glucosa, pero sin alteraciones en la masa de tejido adiposo. Estos hechos revelan que la captación de glucosa por el tejido adiposo juega un rol en la detección y administración de adaptaciones en el metabolismo de carbohidratos. A nivel de laboratorio, se han desarrollado modelos en roedores en los cuales al producir modificaciones genéticas a nivel de adipocitos se produce obesidad pero sin los componentes propios de esta patología (resistencia insulínica, diabetes 2, hígado graso y dislipidemia). Estos hallazgos ponen una vez más en evidencia la existencia de mecanismos regulatorios finos que operan tanto para determinar la cantidad como la distribución del tejido adiposo (Cinti, et al., 2005; Sethi \& Vidal-Puig, 2007).

\section{RESPUESTA DEL TEJIDO ADIPOSO A LA SOBREALIMENTACIÓN}

El tejido adiposo responde a la sobrealimentación mediante un marcado aumento de su masa, a través de mecanismos de hipertrofia e hiperplasia, provocando obesidad clínica y sus repercusiones metabólicas. Una de las complicaciones de mayor prevalencia en la actualidad lo constituye el desarrollo de insulino resistencia. Existen 2 hipótesis que explican la insulino resistencia inducida por la obesidad (Sethi \& Vidal-Puig, 2007).

1. Existiría una deficiencia para acomodar los excesos de energía producidos por la sobrealimentación en el organismo. Esto resultaría en el acumulo de éstos componentes lipídicos en otros órganos como los músculos y el hígado. Este acumulo inapropiado afectaría la respuesta metabólica normal de éstos tejidos al uso metabólico de la glucosa producido por la disminución en ellos de los transportadores de tipo GLUT (Herman \& Kahn, 2006).

2. La sobrecarga nutricional en el tejido adiposo estimularía cambios cuali y cuantitativos en la producción de adipokinas. Estas adipokinas actuarían como moduladores de la sensibilidad a la insulina desencadenando resistencia a la insulina local y sistémica (Trayhurn, 2005).
Cuando el tejido adiposo no puede almacenar de manera adecuada una sobrecarga de nutrientes, éstos se almacenan en otros lugares como el músculo, hígado, corazón y páncreas. Estos tejidos no están diseñados para almacenar grandes cantidades de lípidos siendo más susceptibles a los efectos tóxicos de la propia acumulación de grasa (Unger, 1995). Cada órgano presenta su propia respuesta tóxica. Este daño lipotóxico depende de 3 factores: a) de la magnitud y duración del exceso de nutrientes; b) de la funcionalidad de los mecanismos de transporte y de almacenamiento de ácidos grasos en los tejidos y; c) de la disminución de la capacidad oxidativa del órgano.

La funcionalidad del sistema de transporte de ácidos grasos en los diversos órganos está relacionada con las respuestas individuales de cada órgano a la lipotoxicidad. Existen factores de transcripción, como el SREBP1 C (Steroid Regulatory Element Binding Protein 1), que actúan como vigilante contra la lipotoxicidad en los músculos y otros órganos periféricos. La sobre activación de SREBP1 C en éstos tejidos facilita el depósito de triacilglicéridos a largo plazo. Se favorece principalmente la acumulación de ácidos grasos saturados de cadena larga, los que ejercen un efecto tóxico a nivel de los tejidos. Por otra parte, se ha encontrado el PPAR $\gamma$, un factor adipogenético propio del tejido adiposo, en órganos como el músculo y el hígado. La sobreactivación de este regulador transcripcional estaría también involucrada en la lipotoxicidad a nivel de músculos e hígado que caracteriza a la obesidad y a la resistencia a la isulina (Medina-Gomez et al., 2007).

La asociación de los tres factores ya mencionados determina la calidad y cantidad de los lípidos intracelulares disponibles para regular las señales celulares, lo cual constituye actualmente un terreno de investigación en materia de nuevos enfoques terapéuticos para la obesidad. Existen aún controversias sobre qué tipos de especies lipídicas están relacionadas con la capacidad de producir lipotoxicidad. Generalmente se ha observado que la acumulación ectópica de triacilglicéridos en el tejido hepático y muscular es un signo de lipotoxicidad directamente relacionado con la resistencia a la insulina asociada a la obesidad. Sin embargo, algunos estudios establecen que la distribución ectópica de triglicéridos por sí sola no sería causa de lipotoxicidad. Algunos investigadores consideran que la acumulación de triacilglicéridos en órganos periféricos bajo condiciones de balance energético positivo, reflejarían la capacidad de un determinado órgano de funcionar como depósito de nutrientes. Lo lógico sería pensar que inhibiendo selectivamente la absorción de triacilglicéridos y su consecuente depósito tisular, se reduciría el riesgo de lipotoxicidad. Sin embargo, los estudios muestran una inducción de un estado más tóxico por la acumulación de otros lípidos más reactivos, hecho que se demostró al bloquear genéticamente la expresión (síntesis) del PPAR y en el hígado de ratones ob/ob (genéticamente obesos), en los que la 
ausencia de depósitos de triacilglicéridos en un contexto de balance energético positivo, provoca mayor resistencia insulínica y falla metabólica generalizada (Medina-Gomez et al., 2007; Sethi \& Vidal-Puig, 2007).

Un punto clave en el entendimiento del mecanismo de toxicidad de las diferentes especies lipídicas estaría dado por el estudio de mediadores intracelulares de resistencia insulínica inducida por lípidos. En la circulación los ácidos grasos libres, producto de la lipólisis, son inductores directos de insulino resistencia y diabetes 2 , particularmente en obesos y en pacientes dislipidémicos. Es más, la infusión de lípidos en roedores promueve la gluconeogénesis y la salida de glucosa del hígado. Los niveles de glicemia permanentemente altos provocan una disminución de la secreción de insulina por parte de las células $\beta$ del páncreas a través de mecanismos lipotóxicos aún no bien definidos (Unger, 1995; Bergman \& Ader, 2000).

En el tejido muscular y adiposo el aumento de ácidos grasos libres inhibe la sensibilidad a la insulina y la captación de glucosa estimulada por la insulina. La hipótesis comúnmente aceptada era que la hiperglicemia es provocada por una inhibición de la captación de glucosa por inhibición, por competencia, con los ácidos grasos. Actualmente se postulan mecanismos que provocan cambios a nivel de la composición lipídica de la membrana celular con un marcado aumento de lípidos reactivos en el medio intracelular como el diacil glicerol (DAG) y las ceramidas. Estos lípidos reactivos activarían kinasas como la IRS-I (receptor catalítico de insulina) a través de la fosforilación de residuos de serina, reduciendo la función normal del receptor y el efecto de la insulina. Con respecto a las ceramidas, se ha visto que ciertos derivados de ceramidas, como los gangliósidos asociados a la membrana, se comportan como mediadores importantes en la insulino resistencia inducida por lípidos. Es más, actuarían inhibiendo específicamente la actividad de la enzima glucosil-ceramida sintetasa (la principal enzima en la síntesis de glucoesfingolípidos). Se puede revertir la insulino resistencia en numerosos modelos de obesidad a través de la disminución de los niveles de ceramidas. Cabe destacar, además, que las ceramidas están importantemente involucradas en el desarrollo de la apoptósis o muerte celular programada (Aerts et al., 2007; Straczkowski et al., 2007).

\section{EL TEJIDO ADIPOSO PUEDE REGULAR LA INGESTA DE ALIMENTOS Y EL GASTO ENERGÉTICO}

Como ya se mencionó, el tejido adiposo sintetiza una gran variedad de adipokinas, las que se integran a la acción de otras moléculas reguladoras que generan otros órganos, como es el caso del cerebro y del estómago, y que en conjunto participan en la regulación de la ingesta y del gasto energético (Murphy \& Bloom, 2006). Revisaremos algunas moléculas que participan en estos procesos:
Leptina: Una de las principales adipokinas que libera el tejido adiposo blanco. El aumento de la secreción de esta hormona, conlleva a la disminución de la ingesta de alimentos, al actuar a nivel de hipotálamo, específicamente en el núcleo paraventricular (Cowley et al., 2001).

Apelina: Se ha descubierto que es capaz de regular la contractibilidad cardíaca y al mismo tiempo disminuir la presión sanguínea, pero adicionalmente se ha observado que tiene un efecto similar al de la leptina en el sentido que es responsable de disminuir la ingesta de alimentos (O'Shea et al., 2003).

Aromatasa: Esta es en realidad una enzima que contiene el tejido adiposo que convierte la hormona androstenediona en un estrona. Esta es una hormona que además de inducir la acumulación de grasa mamaria, se ha descubierto que su presencia en humanos aumenta la acción de la leptina y al mismo tiempo, el transporte de la leptina en el cerebro por lo que, indirectamente, disminuye la ingesta de alimentos (Mattsson \& Olsson, 2007).

Adiponectina: Se le ha atribuido un rol cardioprotector y específicamente de disminuir la resistencia a la insulina y cuya acción se logra al actuar a nivel de tejidos periféricos, como el músculo, en el que favorece la entrada de glucosa. Recientemente, los estudios indican un rol doble de la adiponectina en cuanto a la ingesta de alimentos, ya que cuando actúa a nivel del núcleo paraventricular disminuye la ingesta y adicionalmente aumenta la actividad de la UCP-1 por lo que el gasto energético también aumenta. Sin embargo, cuando actúa a nivel del núcleo arcuato del hipotálamo, se observa un aumento de la ingesta de alimentos, y disminuye el gasto energético. Por ello, actualmente se requiere de mayor cantidad de investigaciones sobre el rol de adiponectina a nivel del cerebro (Shklyaev et al., 2003; Qi et al., 2004).

Resistina: Estudios en humanos muestran que esta molécula es secretada por linfocitos mononucleares y por células estromales que se encuentran dentro del tejido adiposo. La acción comprobada de esta adipokina es la de disminuir transitoriamente la ingesta de alimentos, esto es el lapso entre la ingesta y los primeros 90 minutos post ingesta (Tovar et al., 2005).

Actividad 11-hidroxiesteroide deshidrogenada: Esta es una enzima del tejido adiposo blanco que se encarga de convertir el cortisol en cortisona. Se ha encontrado correlación positiva de la actividad de esta enzima con la cantidad de grasa corporal. Aunque en el sentido estricto, la cantidad de corticoides aumenta con el estrés, se ha observado una acción dual de estas hormonas. En general, en la mayoría de las personas, un aumento de los corticoides aumenta el consumo de alimento, pero en un pequeño grupo en iguales circunstancias, disminuye la ingesta de alimentos (Henry \& Clarke, 2008).

En resumen, hay evidencia que el tejido adiposo secreta varias moléculas que tienen la capacidad de disminuir la ingesta de alimentos, de tal manera que la tendencia fisiológica natural de este 
tejido en el organismo, sería la de mantener el peso, y conjuntamente regular el gasto energético. Por otra parte, otros órganos producen hormonas y/o neurotransmisores que aumentan la ingesta de alimentos siendo la principal y la más importante, la ghrelina que es sintetizada por el estómago, pero además se suman otras moléculas como las endorfinas, encefalinas, adrenalina, por mencionar algunas (Murphy \& Bloom, 2006) Por consiguiente, un adecuado peso y un gasto energético que permita conservar este peso, dependerá de la integración de las señales que inhiben la ingesta de alimentos, como de aquellas que la inducen, lo que permite en cada momento controlar la homeostasis energética y de la ingesta. Por lo tanto, actualmente, además de considerar la actividad física como un regulador del peso corporal, cada vez toma mayor fuerza el concepto que la obesidad la debemos entender como un desequilibrio en la función del tejido adiposo, es decir un tejido adiposo normal pasa a convertirse en un tejido adiposo obesogénico.

\section{CONCLUSIONES}

Se sigue investigando activamente en el tejido adiposo y con el paso de los años se han puesto en evidencia una serie de roles y funciones hasta hace poco completamente desconocidas para este tejido, incluyendo la homeostasis energética (metabolismo de lípidos, carbohidratos, control del apetito, termogénesis), el sistema inmunológico, la función reproductiva, la hemostasia y la angiogénesis. Un capítulo de gran actualidad lo constituye el tejido adiposo y su rol tóxico a nivel metabólico (lipotoxicidad) dada su enorme relevancia clínica y potencial terapéutico-farmacológica. Debemos esperar en los próximos años nuevos descubrimientos sobre este particular e importante tejido, que como ya hemos visto, es algo más que un reservorio energético.

\section{REFERENCIAS}

Aerts JM, Ottenhoff R, Powlson AS, Grefhorst A, van Eijk M, Dubbelhuis PF, Aten J, Kuipers F, Serlie MJ, Wennekes T, Sethi JK, O'Rahilly S, Overkleeft HS. 2007. Pharmacological inhibition of glucosylceramide synthase enhances insulin sensitivity. Diabetes 56,1341-1349.

Argyropoulos G, Harper ME. 2002. Uncoupling proteins and thermoregulation. J. Appl. Physiol. 192, 21872198.

Asakura H. 2004. Fetal and neonatal thermoregulation. J. Nippon. Med. Sch. 71, 360-370

Bakker AH, Van Dielen FM, Greve JW, Adam JA, Buurman WA. 2004. Preadipocyte number in omental and subcutaneous adipose tissue of obese individuals. Obes. Res. 12, 488-498.

Bianco AC, Silva JE. 1987. Optimal response of key enzymes and uncoupling protein to cold in BAT depends on local T3 generation. Am. J. Physiol. 253, E309-315.
Bhakoo O. 1974. Minimal rates of oxygen comsumption in small for dates during the first week of life. Arch. Dis. Child. 49, 583-590.

Bergman RN, Ader M. 2000. Free fatty acids and pathogenesis of type 2 diabetes mellitus. Trends. Endocrinol. Metab. 11, 351-356.

Brun LD, Gagne C, Julien P, Tremblay A, Moorjani S, Bouchard C, Lupien PJ. 1989. Familial lipoprotein lipaseactivity deficiency: study of total body fatness and subcutaneous fat tissue distribution. Metabolism 38, 1005-1009.

Cannon B, Nedergaard J. 2004. Brown adipose tissue: function and physiological significance. Physiol. Rev. 84, 277-359.

Cinti S. 2005. The adipose organ. Prostaglandins Leukot. Essent. Fatty Acids 73, 9-15.

Cinti S, Mitchell G, Barbatelli G, Murano I, Ceresi E, Faloia E, Wang S, Fortier M, Greenberg AS, Obin MS. 2005. Adipocyte death defines macrophage localization and function in adipose tissue of obese mice and humans. J. Lipid. Res. 46, 2347-2355.

Cinti S. 2006. The role of brown adipose tissue in human obesity. Nutr. Metab. Cardiovasc. Dis. 16, 569-574.

Cowley MA, Smart JL, Rubinstein M, Cerdán MG, Diano S, Horvath TL, Cone RD, Low MJ. 2001. Leptin activates anorexigenic POMC neurons through a neural network in the arcuate nucleus. Nature 411, 480-484.

Djian P, Phillips M, Green H 1985. The activation of specific gene transcription in the adipose conversion of 3T3 cell. J. Cell. Physiol. 124, 554-556.

Entingh AJ, Taniguchi CM, and Kahn CR. 2003. Bi-directional regulation of brown fat adipogenesis by the insulin receptor. J. Biol. Chem. 278, 33377-33383.

Farmer SR. 2006. Transcriptional control of adipocyte formation. Cell. Metab. 4, 263-273.

Garaulet M, Hernandez-Morante JJ, Lujan J, Tebar FJ, Zamora S. 2006. Relationship between fat cell size and number and fatty acid composition in adipose tissue from different fat depots in overweight/obese humans. Int. J. Obes. 30, 899-905.

Geloen A, Roy PE, Bukowiecki LJ. 1989. Regression of white adipose tissue in diabetic rats. Am. J. Physiol. 257, E547-553.

Gillum RF. 1987. The association of body fat distribution with hypertension, hypertensive heart disease, coronary heart disease, diabetes and cardiovascular risk factors in men and women aged $18-79$ years. J. Chronic. Dis. 40, 421-428.

Green H, Kehinde O. 1975. An established preadipose cell line and its differentiation in culture. II. Factors affecting the adipose conversion. Cell 5, 19-27.

Gregoire FM, Smas CM, Sul HS. 1998. Understanding adipocyte differentiation. Physiol. Rev. 78, 783-809.

Gregoire FM.. 2001. Adipocyte differentiation: from fibroblast to endocrine cell. Exp. Biol. Med. 226, 997-1002.

Halliwell KJ, Fielding BA, Samra JS, Humphreys SM, Frayn KN. 1996. Release of individual fatty acids from human adipose tissue in vivo after an overnight fast. J. Lipid. Res. 37, 18421848.

Hausman GJ. 1987. Identification of adipose tissue primordial in perirenal tissues of pig fetuses:utility of phosphatase histochemistry. Acta Anat. 128, 236-242.

Hausman GJ, Hausman DB. 2006. Search for the preadipocyte progenitor cell. J. Clin. Invest. 116, 3103-3106.

Hager A. 1977. Body fat and adipose tissue cellularity in infants. Metabolism 2, 607-614.

Herman MA, Kahn BB. 2006. Glucose transport and sensing in the maintenance of glucose homeostasis and metabolic harmony. J. Clin. Invest. 116, 1767-1775. 
Henry BA, Clarke IJ. 2008. Adipose tissue hormones and the regulation of food intake. J. Neuroendocrinol. 20 , 842-849.

Hesselink MKC, Mensink M, Schrauwen P. 2003. Human uncoupling protein-3 and obesity: an update. Obes. Res. 11, 1429-1443.

Hirsh J, Batchelor B. 1976. Adipose tissue cellularity in human obesity. J. Clin. Endocrinol. Metab. 5, 299-311.

Kim JK, Gavrilova O, Chen Y, Reitman ML, Shulman GI. 2000. Mechanism of insulin resistance in A-ZIP/F-1 fatless mice. J. Biol. Chem. 275, 8456-8460.

Kowenz-Leutz, E. and Leutz A. 1999. A C/EBP beta isoform recruits the SWI/SNF complex to activate myeloid genes. Mol. Cell. 4, 735-743

Kuk JL, Ross R. 2009. Influence of sex on total and regional fat loss in overweight and obese men and women. Int J. Obes. 33, 629-634

Lekstrom-Himes J, Xanthopoulos KG. 1998. Biological role of the CCAAT/enhancer-binding protein family of transcription factors. J. Biol. Chem. 273, 2854528548.

Mandrup S, Lane MD. 1997. Regulating adipogenesis. J. Biol. Chem. 272, 5367-5370.

Mattsson C, Olsson T. 2007. Estrogens and glucocorticoid hormones in adipose tissue metabolism. Curr. Med. Chem. 14, 2918-2924.

Mauriège $P$, Imbeault $P$, Langin $D$, Lacaille $M$, Alméras $N$, Tremblay A, Després JP. 1999. Regional and gender variations in adipose tissue lipolysis in response to weight loss. J. Lipid. Res. 40, 1559-1571.

Medina-Gomez G, Gray SL, Yetukuri L, Shimomura K, Virtue S, Campbell M, Curtis RK, Jimenez-Linan M, Blount M, Yeo GS, Lopez M, Seppänen-Laakso T, Ashcroft FM, Oresic M, Vidal-Puig A. 2007. PPAR gamma 2 prevents lipotoxicity by controlling adipose tissue expandability and peripheral lipid metabolism. PLoS Genet. 3 (4) e64.

Miner JL. 2004. The adipocyte as an endocrine cell. J. Anim. Sci. 82, 935-941.

Morrison RF, Farmer SR. 2000. Hormonal signaling and transcriptional control of adipocyte differentiation. $J$. Nutr. 130, 3116S-3121S

Murphy KG, Bloom SR. 2006. Gut hormones and the regulation of energy homeostasis. Nature 444, 854-859.

Qi Y, Takahashi N, Hileman SM, Patel HR, Berg AH, Pajvani UB, Scherer PE, Ahima RS. 2004. Adiponectin acts in the brain to decrease body weight. Nat. Med. 10, 524-529.

O'Shea M, Hansen MJ, Tatemoto K, Morris MJ. 2003. Inhibitory effect of apelin-12 on nocturnal food intake in the rat. Nutr. Neurosci. 6, 163-167.

Poissonnet CM, Burdi AR, Garn SM. 1984. The chronology of adipose tissue appearance and disturbance in human fetus. Early Hum. Dev. 10, 1-11

Price W. 1994. Determinants of fetal and neonatal growth. Curr. Opin. Pediatr. 6, 135-141.

Ranganathan G, Unal R, Pokrovskaya I, Yao-Borengasser A, Phanavanh B, Lecka-Czernik B, Rasouli N, Kern PA. 2006. The lipogenic enzymes DGAT1, FAS, LPL in adipose tissue: effects of obesity, insulin resistance and TZD treatment. J. Lipid. Res. 47, 24442450.

Richon VM, Lyle RE, McGehee RE. 1997. Regulation and expression of retinoblastoma proteins p107 and p130 during 3T3-L1 adipocyte differentiation. J. Biol. Chem. 272, 10117-10124.

Ronti T, Lupattelli G, Mannarino E. 2006. The endocrine function of adipose tissue: an update. Clin Endocrinol 64, 355-365.
Rosen ED, Walkey CJ, Puigserver P, Spiegelman BM. 2000. Transcriptional regulation of adipogenesis. Genes Dev. 14, 1293-1307.

Rosen ED, MacDougald OA. 2006. Adipocyte differentiation from the inside out. Nat. Rev. Mol. Cell. Biol. 7, 885-896.

Salans LB, Cushman SW, Weismann RE. 1973. Studies of human adipose tissue: adipose cell size and number in nonobese and obese patients. J. Clin. Invest. 52, 929-941

Sethi JK, Vidal-Puig AJ. 2007. Adipose tissue function and plasticity orchestrate nutritional adaptation. J. Lipid. Res. 48, 1253-1262.

Shao D, Lazar MA. 1997. Peroxisome proliferator activated receptor and CCAA T/enhancer-binding protein and cell cycle status regulate the commitment to adipocyte differentiation. J. Biol. Chem. 272, 2147321478.

Shklyaev S, Aslanidi G, Tennant M, Prima V, Kohlbrenner E, Kroutov V, Campbell-Thompson M, Crawford J, Shek EW, Scarpace PJ, Zolotukhin S. 2003. Sustained peripheral expression of transgene adiponectin offsets the development of diet-induced obesity in rats. Proc. Natl. Acad. Sci. 100, 14217-14222.

Spiegelman BM, Frank M, Green H. 1983. Molecular cloning of mRNA from 3T3 adipocytes. Regulation of mRNA content for glycerophosphate dehydrogenase and other differentiation-dependent proteins during adipocyte development. J. Biol. Chem. 258, 1008310089.

Stephenson T, Budge H, Mostyn A, Pearce S, Webb R and Symonds ME. 2001. Fetal and neonatal adipose maturation: a primary site of cytokine and cytokine-receptor action. Biochem. Soc. Trans. 29, 80-85.

Straczkowski M, Kowalska I, Baranowski M, Nikolajuk A, Otziomek E, Zabielski P, Adamska A, Blachnio A, Gorski J, Gorska M. 2007. Increased skeletal muscle ceramide level in men at risk of developing type 2 diabetes Diabetologia. 50, 2366-2373.

Symonds ME, Bryant MJ, Clarke L, Darby CJ, Lomax MA. 1992. Effect of maternal cold exposure on brown adipose tissue and thermogenesis in the neonatal lamb. J. Phys. 455, 487-502.

Subramanian V, Rothenberg A, Gomez C, Cohen AW, Garcia A, Bhattacharyya S, Shapiro L, Dolios G, Wang R, Lisanti MP, Brasaemle DL. 2004. Perilipin A mediates the reversible binding of CGI-58 to lipid droplets in 3T3-L1 adipocytes. J. Biol. Chem. 279, 4206242071.

Tchkonia T, Giorgadze N, Pirtskhalava T, Tchoukalova Y, Karagiannides I, Forse RA, DePonte M, Stevenson M, Guo W, Han J, Waloga G, Lash TL, Jensen MD, Kirkland JL. 2002. Fat depot origin affects adipogenesis in primary cultured and cloned human preadipocytes. Am. J. Physiol. Regul. Integr. Comp. Physiol. 282, R1286-R1296.

Tovar S, Nogueiras R, Tung LY, Castañeda TR, Vázquez MJ, Morris A, Williams LM, Dickson SL, Diéguez C. 2005. Central administration of resistin promotes short-term satiety in rats. Eur. J. Endocrinol. 153, R1R5.

Trayhurn P. 2005. The biology of obesity. Proc. Nutr. Soc. 64, 31-38.

Tschöp M, Heiman ML. 2001. Rodent obesity models: an overview. Exp. Clin. Endocrinol. Diabetes 109, 307319.

Unger RH. 1995. Lipotoxicity in the pathogenesis of obesity-dependent NIDDM. genetic and clinical implications. Diabetes 44, 863-870. 
Vague J. 1947. La différentiation sexuelle, facteur déterminant des formes de l'obésité. Presse Med 30, 339340.

Valet P, Tavernier G, Castan-Laurell I, Saulnier-Blache JS, Langin D. 2002. Understanding adipose tissue development from transgenic animal models. J. Lipid. Res. 43, 835-860.
Vázquez-Vela ME, Torres N, Tovar AR. 2008. White adipose tissue as endocrine organ and its role in obesity. Arch. Med. Res. 39, 715-728.
Recibido: $16 / 4 / 09$ Aceptado: $11 / 5 / 09$ 